\title{
Unintended pregnancy in Egypt: evidence from the national study on women giving birth in 1999
}

\author{
A.A. Shaheen, ${ }^{1}$ M. Diaaeldin, ${ }^{2}$ M. Chaaya ${ }^{3}$ and Z. El Roueihe ${ }^{3}$

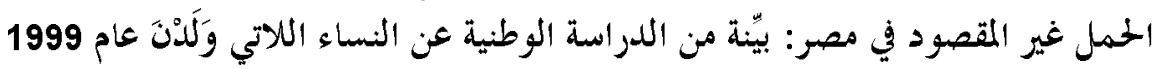

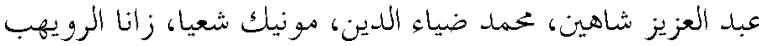

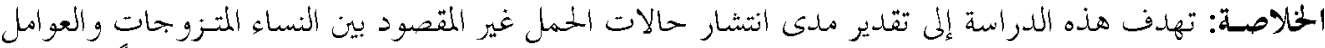

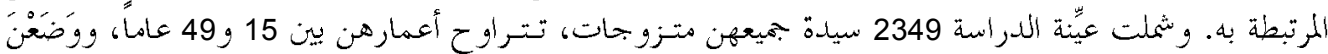

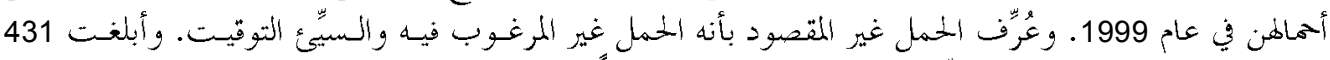

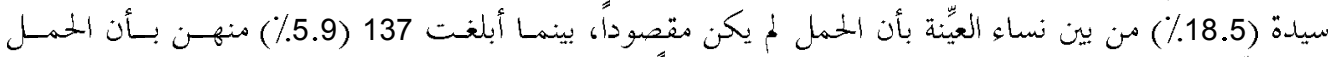

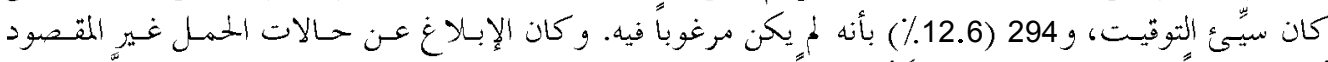

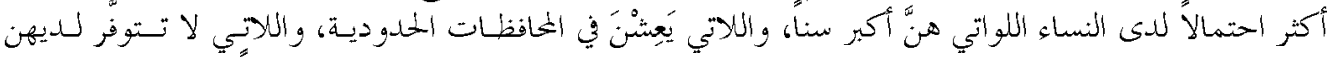

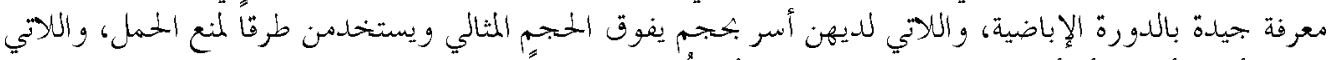

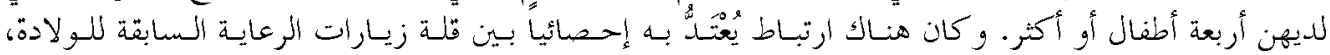

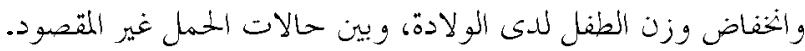

ABSTRACT The current study aimed to estimate the prevalence and correlates of unintended pregnancy among ever-married women. The study sample was 2349 ever-married women aged 15-49 years who gave birth in 1999. Unintended pregnancy was defined as unwanted and mistimed pregnancies. Of these, $431(18.5 \%)$ women reported unintended pregnancy: 137 were mistimed (5.9\%) and 294 were unwanted $(12.6 \%)$. Women of older age, living in frontier governorates, with poor knowledge of the ovulatory cycle, having a more than ideal family size, using contraceptive methods and having 4 or more children were at increased odds of reporting unintended pregnancies. Fewer antenatal care visits and low child weight at birth were significantly associated with unintended pregnancy.

Les grossesses non désirées en Égypte : la situation révélée par l'étude nationale sur les femmes ayant accouché en 1999

RÉSUMÉ La présente étude avait pour objectif d'évaluer la prévalence des grossesses non désirées et les variables qui leur sont associées chez les femmes non célibataires. L'échantillon de l'étude se composait de 2349 femmes, toutes non célibataires, âgées de 15 à 49 ans et ayant accouché en 1999. Une grossesse non désirée a été définie comme une grossesse non volontaire ou accidentelle et inopportune ou non programmée. Sur l'ensemble de l'échantillon, 431 femmes $(18,5 \%)$ ont reconnu avoir eu une grossesse non désirée, inopportune dans 137 cas $(5,9 \%)$ et accidentelle dans 294 cas (12,6\%). La probabilité de grossesse non désirée se trouve augmentée chez les femmes plus avancées en âge, résidant dans les gouvernorats frontaliers, ayant une méconnaissance du cycle ovulatoire, appartenant à une famille déjà nombreuse, utilisant une méthode contraceptive et ayant au moins 4 enfants. II est apparu une association significative entre les grossesses non désirées et l'insuffisance du suivi prénatal et un faible poids de naissance.

${ }^{1}$ Liver Unit, University of Calgary, Alberta, Canada.

${ }^{2}$ United Nations Population Fund, Geneina Office, Sudan.

${ }^{3}$ Faculty of Health Sciences, Department of Epidemiology and Population Health. American University of Beirut, Beirut, Lebanon (Correspondence to M. Chaaya: mchaaya@aub.edu.Ib).

المجلة الصحية لشرق المتو سط، منظمة الصحة العالمية، المجلد الثالث عشر، العدد ؟، V ... 


\section{Introduction}

The most common cause of reproductive mortality is pregnancy and its related problems [1]. At the time of conception, pregnancy may be intended or unintended. Unintended pregnancies can be defined as "pregnancies reported to have been either unwanted (i.e. occurring when no children, or no more children, were desired) or mistimed (i.e. occurring earlier than desired)" [2]. Unintended pregnancy is an important issue to address because the risk factors of unintended pregnancies are similar to those of maternal mortality, and unintended pregnancy is often an indicator of the presence of risk factors for maternal mortality [3].

One of the common results of unintended pregnancy is abortion [1], an outcome for which there are few, if any, data in developing countries as it is not generally reported. In addition, unintended pregnancy is associated with an array of risky health behaviours, such as domestic violence [4], decreased likelihood of breastfeeding initiation or continuation $[5,6]$, and poor antenatal care [7]. In Egypt, poor antenatal care is considered the second most important preventable factor in maternal mortality after substandard obstetric care [8].

The results of studies looking at the relationship between low birth weight and unintended pregnancy are inconsistent. A study using data from the National Longitudinal Study of Youth found "little association" between unwanted pregnancy and low birth weight [9], whereas another study conducted in Ecuador indicated that unwanted, but not mistimed, pregnancies were associated with a higher odds of low birth weight [10].

Concerning the determinants of unintended pregnancy, a recent prospective study in 2 governorates of Upper Egypt revealed that the majority of women never used contraception, and unintended pregnancy was more prevalent in this category compared to those who had ever used [11]. In Harare, a significant association was found between unintended pregnancy and age, with women aged 19 years and below or 35 years and above having a higher risk of unintended pregnancy [12]. Moreover, women with more than 5 children, and women who were unemployed, nulliparous and with low income, were significantly more likely to present with unplanned pregnancy [3].

The objectives of this study were:

- To estimate the prevalence of unintended pregnancies that ended in birth in 1999 among ever-married Egyptian women.

- To assess the sociodemographic, reproductive and nonreproductive health correlates of unintended pregnancy, in particular contraceptive use.

- To explore some health-related outcomes of unintended pregnancy in Egypt.

\section{Methods}

\section{Study sample}

Data were obtained from the most recent Egypt Demographic and Health Survey 2000 (EDHS 2000), which was a crosssectional survey conducted in the first half of the year 2000 by the Ministry of Health and Population and the National Population Council in Egypt [13]. The EDHS 2000 sample included 15573 women from 16357 households from all governorates of Egypt. A total of 2352 respondents were ever-married women aged 15 to 49 years who had given birth in 1999. Out of these, 3 did not provide information about their pregnancy intention, thus making the sample size in the current study 2349 .

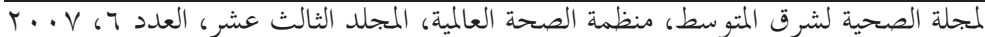




\section{Outcomes}

Pregnancy intention was the main variable of interest for this study. Pregnancies were classified as those that were wanted at the time of conception (intended pregnancy) or mistimed or unwanted (unintended pregnancies) at the time of conception.

\section{Measures}

Selected reproductive health determinants for each woman were: previous terminated pregnancy (yes/no), family planning history (never used contraceptives, used just before the last pregnancy, ever-used), age of woman at first birth $(<18,18-25, \geq 25$ years $)$, birth order of the child (1st, 2nd, 3rd, 4th or more), knowledge about the ovulatory cycle (woman knows/does not know), difference between achieved and desired family size (have ideal number, have more than ideal, have less than ideal) and couple agreement on the reproductive desire (agree, disagree, woman does not know).

Sociodemographic variables included were: age of woman $(<18,18-34, \geq 35$ years) and her education (no education, primary, secondary, higher education). Because of the high percentage of unemployed women, the husband's occupation was used and classified into 3 categories (professional, managerial, clerical and sales; agriculture workers; service persons and manual workers). In addition, place of residence was studied according to type of governorate [urban, frontier, Upper Egypt (rural and urban) and Lower Egypt (rural and urban)].

The selected outcome measures for unintended pregnancy were: child size at birth as reported by the mother (average, large, small); 2 nd dose of polio vaccination status (yes/no), child status in 2000 (alive/dead) and antenatal care (ANC), measured by the numbers of ANC visits $(0,<4, \geq 4$ visits) where 4 is the adequate minimum number of ANC visits according to the World Health Organization [14].

Data on all the above-mentioned variables were obtained from the women's answers.

\section{Statistical analysis}

Bivariate associations between unintended pregnancy and each of the determinants and outcomes were checked. These associations were described by computing odds ratios (OR) with $95 \%$ confidence intervals (CI) and $P$ values, where $P \leq 0.05$ indicated a significant association. Only variables that were significant at the bivariate level were entered into a multivariable logistic regression model to estimate adjusted odds ratios (AOR) of unintended pregnancy and the corresponding $95 \% \mathrm{CI}$ and $P$ values. All analyses were conducted using SPSS for Windows, version 12.0.

\section{Results}

\section{Sociodemographic characteristics}

The mean age of the sample of women was 26.4 years, standard deviation (SD) 6.03 . The study respondents were similar to the overall EDHS respondents regarding region of residence, education, husband's occupation and contraceptive use. There were observed differences in the age of women and family size (measured as number of live children at the time of the survey). The proportion of the study sample aged $\geq 35$ years was lower than the overall EDHS respondents ( $10.4 \%$ and $40.6 \%$ respectively) and most of the study respondents had 1 or 2 children, while most of the overall EDHS respondents had $\geq 4$ children (Table 1). However, these differences were not statistically significant and the study sample was representative of EDHS 2000 participants and all Egypt governorates. 


\begin{tabular}{|c|c|c|c|c|}
\hline \multirow[t]{2}{*}{ Variable } & \multicolumn{2}{|c|}{$\begin{array}{c}\text { Study sample } \\
(n=2349)\end{array}$} & \multicolumn{2}{|c|}{$\begin{array}{l}\text { EDHS 2000 } \\
(n=15573)\end{array}$} \\
\hline & No. & $\%$ & No. & $\%$ \\
\hline \multicolumn{5}{|l|}{ Region } \\
\hline Urban governorates & 369 & 15.7 & 3102 & 19.9 \\
\hline Lower Egypt, urban & 256 & 10.9 & 1831 & 11.8 \\
\hline Lower Egypt, rural & 608 & 25.9 & 4277 & 27.5 \\
\hline Upper Egypt, urban & 262 & 11.2 & 1670 & 10.7 \\
\hline Upper Egypt, rural & 699 & 29.8 & 3743 & 24.0 \\
\hline Frontier governorates & 155 & 6.6 & 950 & 6.1 \\
\hline \multicolumn{5}{|l|}{ Age (years) } \\
\hline$<18$ & 86 & 3.7 & 359 & 2.3 \\
\hline $18-34$ & 2019 & 86.0 & 8899 & 57.1 \\
\hline$\geq 35$ & 244 & 10.4 & 6315 & 40.6 \\
\hline \multicolumn{5}{|c|}{ Family size (no. of children) } \\
\hline 0 & 232 & 9.8 & 1489 & 9.6 \\
\hline $1-2$ & 962 & 40.9 & 5159 & 33.1 \\
\hline 3 & 540 & 23.0 & 2987 & 19.2 \\
\hline$\geq 4$ & 618 & 26.3 & 5938 & 38.1 \\
\hline \multicolumn{5}{|l|}{ Woman's education } \\
\hline None & 866 & 36.9 & 6613 & 42.5 \\
\hline Primary & 336 & 14.3 & 2827 & 18.2 \\
\hline Secondary or higher & 1147 & 48.8 & 6133 & 39.4 \\
\hline \multicolumn{5}{|l|}{ Partner's occupation } \\
\hline $\begin{array}{l}\text { Professional, manager } \\
\text { clerical or technical }\end{array}$ & 775 & 33.0 & 5092 & 32.7 \\
\hline Agriculture & 452 & 19.2 & 2858 & 18.4 \\
\hline Service or manual & 997 & 42.4 & 5921 & 38.0 \\
\hline Don't know or missing & 126 & 5.4 & 1702 & 10.9 \\
\hline \multicolumn{5}{|c|}{ History of contraceptive use } \\
\hline No & 456 & 19.4 & 4044 & 26.0 \\
\hline Yes & 1865 & 80.6 & 11529 & 74.0 \\
\hline
\end{tabular}

\section{Prevalence and determinants of unintended pregnancy}

Unintended pregnancy that ended in birth in 1999 was reported by 431 women $(18.4 \%)$ : mistimed pregnancies were $137(5.8 \%)$ and unwanted pregnancies were 294 (12.5\%). In the bivariate analysis of pregnancy intention and sociodemographic variables the following variables were significantly associated with unintended pregnancy: age, place of residence, education and husband's occupation. Thus unintended pregnancy was more prevalent among older age groups, women living in Upper (rural and urban) Egypt,

المجلة الصحية لشرق المتو سط، منظمة الصحة العالمية، المجلد الثالث عشر، العدد Y، V... 
Table 2 Distribution of ever-married women aged 15-49 years who gave birth in 1999 ( $n=2349$ ) by pregnancy intention, according to selected sociodemographic characteristics

\begin{tabular}{|c|c|c|c|c|c|c|c|}
\hline \multirow[t]{2}{*}{ Variable } & \multicolumn{2}{|c|}{$\begin{array}{l}\text { Intended } \\
\text { pregnancy } \\
(n=1918)\end{array}$} & \multicolumn{2}{|c|}{$\begin{array}{l}\text { Unintended } \\
\text { pregnancy } \\
(n=431)\end{array}$} & \multirow[t]{2}{*}{ OR } & \multirow[t]{2}{*}{$95 \% \mathrm{Cl}$} & \multirow[t]{2}{*}{$P$-value } \\
\hline & No. & $\%$ & No. & $\%$ & & & \\
\hline \multicolumn{8}{|l|}{ Age (years) } \\
\hline $18-34$ & 1698 & 84.1 & 321 & 15.9 & 1 & & \\
\hline$<18$ & 84 & 97.7 & 2 & 2.3 & 0.13 & $0.03-0.52$ & 0.004 \\
\hline$\geq 35$ & 136 & 55.7 & 108 & 44.3 & 4.20 & $3.18-5.55$ & $<0.001$ \\
\hline \multicolumn{8}{|l|}{ Region } \\
\hline Urban governorates & 315 & 85.4 & 54 & 14.6 & 1 & & \\
\hline Lower Egypt, urban & 219 & 85.5 & 37 & 14.5 & 0.99 & $0.63-1.55$ & 0.950 \\
\hline Lower Egypt, rural & 514 & 84.5 & 94 & 15.5 & 1.07 & $0.74-1.53$ & 0.727 \\
\hline Upper Egypt, urban & 207 & 79.0 & 55 & 21.0 & 1.55 & $1.02-2.35$ & 0.038 \\
\hline Upper Egypt, rural & 527 & 75.4 & 172 & 24.6 & 1.90 & $1.36-2.66$ & $<0.001$ \\
\hline Frontier governorates & 136 & 87.7 & 19 & 12.3 & 0.82 & $0.47-1.43$ & 0.474 \\
\hline \multicolumn{8}{|l|}{ Woman's education } \\
\hline None & 663 & 76.6 & 203 & 23.4 & 1 & & \\
\hline Primary & 263 & 78.3 & 73 & 21.7 & 0.91 & $0.67-1.23$ & 0.526 \\
\hline Secondary or higher & 992 & 86.5 & 155 & 13.5 & 0.51 & $0.41-0.64$ & $<0.001$ \\
\hline \multicolumn{8}{|l|}{ Partner's occupation } \\
\hline $\begin{array}{l}\text { Professional, managerial, } \\
\text { clerical or technical }\end{array}$ & 636 & 82.1 & 139 & 17.9 & 1 & & \\
\hline Agriculture & 349 & 77.2 & 103 & 22.8 & 1.35 & $1.01-1.80$ & 0.040 \\
\hline Service or manual & 829 & 83.1 & 168 & 16.9 & 0.93 & $0.72-1.19$ & 0.549 \\
\hline
\end{tabular}

Totals may be less than 2349 due to missing observations.

$\mathrm{OR}=$ odds ratio; $\mathrm{Cl}=$ confidence interval.

women having primary or no education and those whose husband worked in the agriculture sector (Table 2).

The relationship of unintended pregnancy with reproductive health variables showed that previous termination of pregnancy, ever-use or use of contraception before last pregnancy, having more than 2 children, $<18$ years or $\geq 25$ years of age at first pregnancy, lack of knowledge about the ovulatory cycle, having more than the ideal number of children, 3rd or 4th birth order and disagreement or ignorance about husband's desire for having children were significantly associated with increased probability of unintended pregnancy (Table 3).
The binomial logistic regression analysis indicated that region, women's age, knowledge of the ovulatory cycle, ideal family size, use of contraceptive methods and the child's order in family were significantly related to unintended pregnancy (Table 4). Compared with women living in urban governorates, women living in frontier governorates were less likely to report their pregnancy as unintended (AOR $=0.49,95 \%$ CI: $0.26-0.92)$. Women aged 35 years or older were more likely to report their pregnancy as unintended compared with women aged $18-35$ years, $(A O R=$ $1.61,95 \%$ CI: $1.14-2.26)$. Women who did not know about their ovulatory cycle were 


\begin{tabular}{|c|c|c|c|c|c|c|c|}
\hline \multirow[t]{2}{*}{ Variable } & \multicolumn{2}{|c|}{$\begin{array}{l}\text { Intended } \\
\text { pregnancy } \\
(n=1918)\end{array}$} & \multicolumn{2}{|c|}{$\begin{array}{l}\text { Unintended } \\
\text { pregnancy } \\
(n=431)\end{array}$} & \multirow[t]{2}{*}{ OR } & \multirow[t]{2}{*}{$95 \% \mathrm{Cl}$} & \multirow[t]{2}{*}{$P$-value } \\
\hline & No. & $\%$ & No. & $\%$ & & & \\
\hline \multicolumn{8}{|l|}{ Ever had terminated pregnancy } \\
\hline No & 1549 & 83.7 & 302 & 16.3 & 1 & & \\
\hline Yes & 369 & 74.1 & 129 & 25.9 & 1.79 & $1.42-2.27$ & $<0.001$ \\
\hline \multicolumn{8}{|l|}{ Contraceptive history } \\
\hline Never used & 660 & 86.5 & 103 & 13.5 & 1 & & \\
\hline Just before last pregnancy & 241 & 75.8 & 77 & 24.2 & 2.05 & $1.47-2.85$ & $<0.001$ \\
\hline Ever-used & 1014 & 80.3 & 249 & 19.7 & 1.57 & $1.23-2.02$ & $<0.001$ \\
\hline \multicolumn{8}{|l|}{ Birth order of child } \\
\hline 1st or 2nd & 1107 & 93.5 & 77 & 6.5 & 1 & & \\
\hline $3 r d$ & 365 & 85.9 & 60 & 14.1 & 2.36 & $1.65-3.38$ & $<0.001$ \\
\hline 4 th or more & 446 & 60.3 & 294 & 39.7 & 9.48 & $7.21-12.5$ & $<0.001$ \\
\hline \multicolumn{8}{|c|}{ Woman's age at first birth (years) } \\
\hline $18-24$ & 1276 & 82.3 & 274 & 17.7 & 1 & & \\
\hline$<18$ & 300 & 73.9 & 106 & 26.1 & 1.65 & $1.27-2.13$ & $<0.001$ \\
\hline$\geq 25$ & 342 & 87.0 & 51 & 13.0 & 0.69 & $0.50-0.96$ & 0.026 \\
\hline \multicolumn{8}{|c|}{$\begin{array}{l}\text { Woman's knowledge of ovulatory } \\
\text { cycle }\end{array}$} \\
\hline Knows & 481 & 87.0 & 72 & 13.0 & 1 & & \\
\hline Does not know & 1437 & 80.0 & 359 & 20.0 & 1.57 & $1.37-1.80$ & $<0.001$ \\
\hline \multicolumn{8}{|l|}{$\begin{array}{l}\text { Difference between ideal and } \\
\text { achieved family size }\end{array}$} \\
\hline Ideal & 515 & 86.0 & 84 & 14.0 & 1 & & \\
\hline More than ideal & 210 & 52.4 & 191 & 47.6 & 5.58 & $4.12-7.55$ & $<0.001$ \\
\hline Less than ideal & 1193 & 88.4 & 156 & 11.6 & 0.80 & $0.60-1.07$ & 0.128 \\
\hline \multicolumn{8}{|l|}{ Couple's desire for family size } \\
\hline Agree & 1226 & 84.3 & 228 & 15.7 & 1 & & \\
\hline Disagree & 455 & 78.6 & 124 & 21.4 & 1.47 & $1.15-1.87$ & 0.002 \\
\hline Don't know & 213 & 76.1 & 67 & 23.9 & 1.69 & $1.24-2.30$ & 0.001 \\
\hline
\end{tabular}

Totals may be less than 2349 due to missing observations. $\mathrm{OR}=$ odds ratio; $\mathrm{Cl}=$ confidence interval.

more likely to report unintended pregnancy than those who knew (AOR $=1.57,95 \%$ CI: 1.10-2.25). Women who had achieved more than their ideal family size had higher likelihood of unintended pregnancy than those who had achieved ideal family size $(\mathrm{OR}=2.70,95 \%$ CI: 1.90-3.84). Compared with women who had never used contracep- tive methods, the odds of unintended pregnancy were higher among those who had ever used these methods and those who had used them just before last pregnancy $(\mathrm{OR}=$ $1.55,95 \%$ CI: $1.12-2.14$ OR $=1.64,95 \%$ CI: $1.10-2.43$, respectively). Considering the birth order of the child, women who $\mathrm{had} \geq 4$ children were 4.42 times $(95 \% \mathrm{CI}$ : 
Table 4 Adjusted odds ratios (AOR) from binomial logistic regression of pregnancy intention by selected determinants

\begin{tabular}{|c|c|c|c|}
\hline Variable & AOR & $95 \% \mathrm{Cl}$ & $P$-value \\
\hline \multicolumn{4}{|l|}{ Region } \\
\hline Urban & 1 & & \\
\hline Lower Egypt, urban & 0.86 & $0.51-1.46$ & 0.576 \\
\hline Lower Egypt, rural & 0.79 & $0.51-1.23$ & 0.294 \\
\hline Upper Egypt, urban & 1.35 & $0.83-2.19$ & 0.223 \\
\hline Upper Egypt, rural & 1.36 & $0.89-2.08$ & 0.161 \\
\hline Frontier & 0.49 & $0.26-0.92$ & 0.028 \\
\hline \multicolumn{4}{|l|}{ Father's occupation } \\
\hline Professional or managerial & 1 & & \\
\hline Agriculture & 0.93 & $0.63-1.37$ & 0.714 \\
\hline Service or manual & 0.84 & $0.62-1.15$ & 0.281 \\
\hline \multicolumn{4}{|l|}{ Woman's' education } \\
\hline None & 1 & & \\
\hline Primary & 1.05 & $0.73-1.52$ & 0.778 \\
\hline Secondary or higher & 1.03 & $0.72-1.47$ & 0.868 \\
\hline \multicolumn{4}{|l|}{ Age of woman (years) } \\
\hline $18-34$ & 1 & & \\
\hline$<18$ & 0.37 & $0.09-1.58$ & 0.181 \\
\hline$\geq 35$ & 1.61 & $1.14-2.26$ & 0.007 \\
\hline \multicolumn{4}{|l|}{ Ever had terminated pregnancy } \\
\hline No & 1 & & \\
\hline Yes & 1.14 & $0.86-1.51$ & 0.365 \\
\hline \multicolumn{4}{|l|}{$\begin{array}{l}\text { Woman's knowledge of ovulatory } \\
\text { cycle }\end{array}$} \\
\hline Knows & 1 & & \\
\hline Does not know & 1.57 & $1.10-2.25$ & 0.012 \\
\hline \multicolumn{4}{|l|}{$\begin{array}{l}\text { Difference between ideal and } \\
\text { achieved family size }\end{array}$} \\
\hline Ideal & 1 & & \\
\hline More than ideal & 2.70 & $1.90-3.84$ & $<0.001$ \\
\hline Less than ideal & 0.85 & $0.61-1.18$ & 0.328 \\
\hline \multicolumn{4}{|l|}{ Couple's desire for family size } \\
\hline Agree & 1 & & \\
\hline Disagree & 1.08 & $0.80-1.45$ & 0.633 \\
\hline Don't know & 1.38 & $0.94-2.03$ & 0.101 \\
\hline \multicolumn{4}{|l|}{ Age at first birth (years) } \\
\hline $18-24$ & 1 & & \\
\hline$<18$ & 0.95 & $0.68-1.31$ & 0.739 \\
\hline$\geq 25$ & 1.23 & $0.83-1.82$ & 0.302 \\
\hline \multicolumn{4}{|l|}{ History of contraceptive use } \\
\hline Never used & 1 & & \\
\hline Used before last pregnancy & 1.64 & $1.10-2.43$ & 0.015 \\
\hline Ever-used & 1.55 & $1.12-2.14$ & 0.008 \\
\hline
\end{tabular}




\begin{tabular}{lcrr}
\hline $\begin{array}{l}\text { Table } 4 \text { Adjusted odds ratios (AOR) from binomial logistic } \\
\text { regression of pregnancy intention by selected determinants } \\
\text { (concluded) }\end{array}$ & AOR & $\mathbf{9 5 \% ~ C l}$ & $\boldsymbol{P}$-value \\
\hline Variable & & & \\
\hline $\begin{array}{l}\text { Birth order of child } \\
\text { 1st or 2nd }\end{array}$ & 1 & & \\
3rd & 1.38 & $0.92-2.07$ & 0.125 \\
4th or more & 4.42 & $3.02-6.48$ & $<0.001$ \\
\hline
\end{tabular}

Totals may be less than 2349 due to missing observations. $\mathrm{OR}=$ odds ratio; $\mathrm{Cl}=$ confidence interval.

3.02-6.48) more likely to report their pregnancy as unintended compared with those who had 1 or 2 children (Table 4 ).

\section{Outcome of unintended pregnancy}

Among the selected pregnancy outcomes, only the size of the newborn, as reported by mothers, and the number of ANC visits were significantly associated with unintended pregnancy. Women who reported unintended pregnancy were more likely to report the child size at birth to be smaller or larger than average size compared with women who did not report unintended pregnancy $(\mathrm{OR}=1.34,95 \% \mathrm{CI}: 1.02-1.76$; OR $=2.25,95 \%$ CI: $1.48-3.44$, respectively). In addition, women who reported unintended pregnancy were significantly more likely to receive no ANC or $<4$ ANC visits compared to those who did not report unintended pregnancy $(\mathrm{OR}=1.56,95 \% \mathrm{CI}$ : 1.24-1.96; OR $=1.41,95 \%$ CI: $1.03-1.93$ respectively) (Table 5).

\section{Discussion}

With an annual population growth rate of 1.8 and a total fertility rate of 3.3 , unplanned pregnancy in Egypt - the most populous Arab country-is an important reproductive issue to address, especially given that over one-third of all pregnancies were reported to be unintended in 1995 [15]. This rate is lower than that reported in the United States (US), where almost half of the pregnancies in 1994 were unintended [16], and in Japan, where the rate of unintended pregnancy according to a 2002 survey was $46 \%$ [17]. However, the US and the Japan rates were calculated among all females, while the Egypt rate is only among ever-married females. On the other hand, the Egyptian rate of unintended pregnancy is closer to that found in the Islamic Republic of Iran, where the rate was $35 \%$ [18]. It is much higher however than other African countries such as Nigeria, where the rate was $14 \%$ in 2003 [19].

Almost 1 in 5 women in the 1999 survey in Egypt reported an unintended pregnancy, mostly unwanted. This prevalence does not reflect the true magnitude of the problem, but can rather be considered as an underestimate since it was only calculated among ever-married women, and those whose pregnancies ended in birth. However, it is lower than the prevalence of unintended pregnancy that ended in birth in $1995(36.0 \%)$ [15]. This decline could be due to the effect of various intervention programmes in the area of maternal health that were implemented in Egypt in the 1990s. In 1984, the National Population Council was established and headed by the

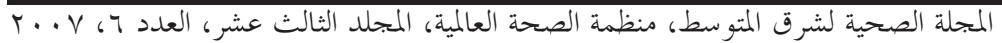




\begin{tabular}{|c|c|c|c|c|c|c|c|}
\hline \multirow[t]{2}{*}{ Variable } & \multicolumn{2}{|c|}{$\begin{array}{l}\text { Intended } \\
\text { pregnancy } \\
(n=1918)\end{array}$} & \multicolumn{2}{|c|}{$\begin{array}{l}\text { Unintended } \\
\text { pregnancy } \\
(n=431)\end{array}$} & \multirow[t]{2}{*}{ OR } & \multirow[t]{2}{*}{$95 \% \mathrm{Cl}$} & \multirow[t]{2}{*}{$P$-value } \\
\hline & No. & $\%$ & No. & $\%$ & & & \\
\hline \multicolumn{8}{|c|}{ Child size at birth } \\
\hline Average & 1540 & 80.3 & 314 & 72.9 & 1 & & \\
\hline Large & 74 & 3.9 & 34 & 7.9 & 2.25 & $1.48-3.44$ & $<0.001$ \\
\hline Small & 304 & 15.8 & 83 & 19.3 & 1.34 & $1.02-1.76$ & 0.035 \\
\hline \multicolumn{8}{|c|}{ Received 2nd polio dose } \\
\hline No & 129 & 15.6 & 25 & 12.8 & 1 & & \\
\hline Yes & 698 & 84.4 & 171 & 87.2 & 1.26 & $0.80-2.00$ & 0.318 \\
\hline \multicolumn{8}{|c|}{ Child alive in 2000} \\
\hline No & 44 & 2.5 & 6 & 1.5 & 1 & & \\
\hline Yes & 1687 & 99.5 & 394 & 98.5 & 1.71 & $0.73-4.05$ & 0.220 \\
\hline \multicolumn{8}{|c|}{ No. of antenatal care visits } \\
\hline$\geq 4$ & 953 & 49.7 & 170 & 39.4 & 1 & & \\
\hline 0 & 698 & 36.4 & 194 & 45 & 1.56 & $1.24-1.96$ & $<0.001$ \\
\hline$<4$ & 267 & 13.9 & 67 & 15.5 & 1.41 & $1.03-1.93$ & 0.033 \\
\hline
\end{tabular}

Totals may be less than 2349 due to missing observations.

$\mathrm{OR}=$ odds ratio; $\mathrm{Cl}=$ confidence interval.

President of Egypt because political leaders were concerned about the population demography in Egypt and government efforts were directed toward increasing the awareness and prevalence of family planning [20]. Effective policies were in place after the International Conference on Population and Development (ICPD) in 1994 where the role of nongovernmental organizations was strengthened. The number of family planning units rose from 3764 in 1980 to 4356 in 1990 [20]. Prevalence of contraceptive use increased from $24.2 \%$ for any method and $22.8 \%$ for modern methods in 1990 to $47.9 \%$ for any method and $45.5 \%$ for modern methods in 1995. Furthermore, the total fertility rate dropped from 5.28 in 1980, to 4.41 in 1988 , then to 3.63 in 1995 [20].

One important determinant of unintended pregnancy is the use of contracep- tion. However, the direction of the relation between these 2 variables is inconsistent within the literature. In the present study, women who had tried contraceptive methods prior to the last pregnancy which ended in birth in 1999 were more likely to have unintended pregnancy than those who never tried these methods. Casterline et al. studied unintended fertility in 2 governorates in Upper Egypt in 1997 and reported that the majority of women were nonusers of contraceptives (73.6\%) and had higher unintended pregnancy rates compared with those who have ever-used contraceptive methods [11]. Casterline et al. encouraged family planning programmes to address nonuser groups [11]. The findings of this study shed light on the important issues of contraceptive failure and the quality of contraceptive services. 
The selection of a suitable contraceptive method, its quality and efficiency, knowledge about its utilization and the woman's compliance are important factors to be assessed and addressed in Egypt. The present national study offers evidence that providing family planning methods to target more women is not enough to prevent unintended pregnancies, and that this provision should be associated with high quality service. In other words, it might be time to address the qualitative aspects of reproductive health programmes rather than only their quantitative aspects. Looking at the components of reproductive health services and the way they are delivered are important challenges to improving the quality aspects. In addition, other comprehensive and holistic social and economical services and programmes should be taken into consideration. Furthermore, our study revealed that nonusers of contraceptives comprised $55.1 \%$ of the sample and they had the lowest unintended pregnancy rates, which further emphasizes contraceptive failure, rather than nonuse, as a predictor of unintended pregnancies. Consequently, higher programme priority should entail providing contraceptive users with good quality services and information to avoid unintended pregnancy $[21,22]$.

The current study also showed a strong association between unintended pregnancy and deficient knowledge about the ovulatory cycle. This relationship should be interpreted with caution, as the information about knowledge of the ovulatory cycle was obtained by only 1 yes/no question. However, this finding highlights the need for health education regarding family planning and for further investigation of this issue. Obviously, a deficient knowledge of the ovulatory cycle for this group of women might lead to contraceptive failure and thus unintended pregnancies.
Overall, our study findings were consistent with the published literature regarding the sociodemographic determinants of unintended pregnancy. Analysis of the data at the bivariate level showed a significant relationship between pregnancy intention and women's age, education and area of residence. Women aged $\geq 35$ years were more likely to have unintended pregnancy compared with those aged 18-34 years. In contrast, those aged $<18$ years were less likely to report unintended pregnancy. The most obvious interpretation of this finding is that the former group, as opposed to the latter, could have achieved their desired family size. Unintended pregnancy in the $<18$ years group is a high figure and considered a serious problem [3]. Education was also an important determinant of unintended pregnancy at the bivariate level as women with secondary or higher education had lower odds of having unintended pregnancies. This could be explained by the potentially higher ability of the educated women to receive and understand the family planning messages, and their use of effective contraceptive methods. Concerning the residence, Upper Egypt governorates, both urban and rural, had the highest proportion of unintended pregnancies. Upper Egypt governorates are remote areas characterized by a high prevalence of illiteracy, poor housing conditions, higher rates of fertility and limited provision and utilization of social services [11].

With respect to health outcomes, only child size and ANC were associated with unintended pregnancy. On the other hand, the results regarding child status should be interpreted cautiously as the numbers of live children were 2081 (88.5\%), dead children $50(2.1 \%)$ and unknown status $220(9.4 \%)$. Taking the last 2 categories into consideration could have influenced

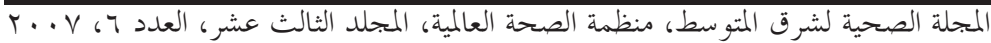


our estimates. The absence of a significant association between unintended pregnancy and the polio vaccination status of the child could be due to the compulsory vaccination and the availability of free medical services for children.

\section{Study limitations}

The EDHS Egypt 2000 was a crosssectional survey that looked retrospectively at women's pregnancy intention and its related determinants and outcomes. Our study results should be cautiously interpreted in view of the limitations of the cross-sectional design.

Women with unintended pregnancy are usually at a higher risk of abortion. Because of the unavailability of data on abortion in Egypt, the current study only addressed women who had pregnancies that ended in childbirth. Furthermore, this study only surveyed ever-married women. These 2 factors together mean that a key limitation of the study was underestimating the prevalence of unintended pregnancy.

Unintended pregnancy in this study refers to unwanted and mistimed pregnancies. It has been suggested in the literature that unwanted and mistimed pregnancies differ with respect to their determinants and outcomes [23], which necessitates further studies to examine these differences.

The prevalence of contraceptive use might have been underestimated due to recall bias. The variables "child size" and "knowledge of the ovulatory cycle" are based solely on the mother's response, thus making these measures subjective.

\section{Conclusion}

There is no doubt that understanding of the determinants of unintended pregnancy will lead to improvements in efforts to avoid such pregnancies, and improve the well-being of women and children [7]. The study of unintended pregnancy offers public health practitioners and demographers the chance to understand fertility patterns and to plan and implement more efficient and successful interventions regarding maternal and child health. Moreover, this study targets Egyptian women of different sociodemographic status and with different reproductive health behaviours than their peers in developed countries. In Egypt, due to the high population density, looking at unintended pregnancy and its determinants provides valuable information for policymakers and public health professionals to address maternal and child health policies and implement interventions. Addressing this issue is timely and should be linked with the important reproductive health programmes and interventions addressing maternal and child health, which took place during the last decade in Egypt [8]. Unintended pregnancy may be a major outcome measure for such programmes and understanding and addressing its determinants could improve these programmes.

Based on the findings of the study, we recommend more interventions concerning reproductive health programmes and services, whereby qualitative aspects of the programmes should be taken into consideration and more care given to promoting reproductive health awareness of women in Upper Egypt. Since pregnancy intention is not recognized as an "individual product", but as a multidimensional product of social, cultural and economical power [7], other social and economical interventions should be implemented in Upper Egypt. Further prospective cohort studies on pregnant women are also required. 


\section{References}

1. Grimes DA. The role of hormonal contraceptives: The morbidity and mortality of pregnancy: still risky business, American. American journal of obstetrics and gynecology, 1994, 170(5 Suppl.):1489-94.

2. Brown SS, Eisenberg L. The best intentions: unintended pregnancy and the well-being of children and families. Washington, DC, National Academy Press, 1995.

3. Forrest JD et al. Epidemiology of unintended pregnancy and contraceptive use. American journal of obstetric and gynecology, 1994, 170(5):1485-9.

4. Donovan P. Physical violence toward pregnant women is more likely to occur when pregnancy was unintended. Family planning perspectives, 1995, 27(5):222-

5. Taylor JS, Cabral HJ. Are women with an unintended pregnancy less likely to breastfeed? Journal of family practice, 2002, 51(5):431-6.

6. Dye TD et al. Unintended pregnancy and breast-feeding behavior, American journal of public health, 1997, 87(10):1709-11.

7. Santelli $\mathrm{J}$ et al. The measurement and meaning of unintended pregnancy. Perspective on sexual and reproductive health, 2003, 35(2):94-101.

8. Campbell $\mathrm{O}$ et al. National maternal mortality ratio in Egypt halved between 1992 93 and 2000. Bulletin of the World Health Organization, 2005, 83(6):462-70.

9. Joyce T, Kaestner R, Korenman S. The effect of pregnancy intention on child development. Demography, 2000, 37(1):8394.

10. Eggleston E, Tsui AO, Kotelchuck M. Unintended pregnancy and low birthweight in Ecuador. American journal of public health, 2001, 91(5):808-10.
11. Casterline JB, El-Zanatay F, El-Zein LO. Unmet need and unintended fertility: longitudinal evidence from Upper Egypt. International family planning perspectives, 2003, 29(4):158-66

12. Mbizvo MT et al. Unplanned pregnancies in Harare: what are the social and sexual determinants? Social science \& medicine, 1997, 45(6):937-42.

13. El-Zanaty F, Way A. Egypt Demographic and Health Survey 2000. Calverton, Maryland and Cairo, Egypt, Ministry of Health and Population, National Population Council and ORC Macro, 2001.

14. Antenatal care. Report of a technical working group: maternal and newborn health, safe motherhood. Geneva, World Health Organization, 1996 (WHO/FRH/ MSM/96.8).

15. El-Zanaty FH et al. Egypt Demographic and Health Survey 1995. Calverton, Maryland and Cairo, Egypt, Ministry of Health and Population, National Population Council and Macro International, Inc, 1996.

16. Henshaw SK. Unintended pregnancy in the United States. Family planning perspectives, 1998, 30(1):24-9.

17. Goto A et al. Factors associated with unintended pregnancy in Yamagata, Japan. Social science \& medicine, 2002 , 54(7):1065-79.

18. Abbasi-Shavazi MJ et al. Unintended pregnancies in the Islamic Republic of Iran: levels and correlates. Asian-Pacific population journal, 2004, 19(1):27-38.

19. The Alan Guttmacher Institute. Reducing unintended pregnancy in Nigeria. Research brief, 2005, 4:1-8.

20. Zohry AG. Population policies and family planning program in Egypt: evolution and performance. In: CDC 26th annual

المجلة الصحية لشرق المتو سط، منظمة الصحة العالمية، المجلد الثالث عشر، العدد ب، V... 
seminar on population issues in the Middle East, Africa and Asia. Cairo, Cairo Demographic Center, 1997:194-211.

21. Jain A, Should eliminating unmet need for contraception continue to be a program priority? International family planning perspectives, 1999, 25(Suppl.):S39-43, S49.

22. Blanc AK, Curtis S, Croft TN. Monitoring contraceptive continuation: links to fertility outcomes and quality of care. Studies in family planning, 2002, 33(2):127-40.

23. D'Angelo DV et al. Differences between mistimed and unwanted pregnancies among women who have live births. Perspectives on sexual and reproductive health, 2004, 36(5):192-7.

\section{Mote from the Editor}

We wish to draw the kind attention of our potential authors to the importance of applying the editorial requirements of the EMHJ when preparing their manuscripts for submission for publication. These provisions can be seen in the Guidelines for authors, which are published at the end of every issue of the Journal. We regret that we are unable to accept papers that do not conform to the editorial requirements. 